\title{
Poultry: since and technologies
}

\section{FUNCTIONAL EGG PRODUCTION. I. THE ROLE OF $\omega$-3 POLYUNSATURATED FATTY ACIDS}

\author{
(review)
}

\author{
A.Sh. KAVTARASHVILI, I.L. STEFANOVA, V.S. SVITKIN, E.N. NOVOTOROV \\ Federal Scientific Center All-Russian Research and Technological Poultry Institute RAS, Federal Agency of Scientific \\ Organizations, 10, ul. Ptitsegradskaya, Sergiev Posad, Moscow Province, 141311 Russia, e-mail alexk@vnitip.ru (cor- \\ responding author),dp.vniipp@mail.ru,89267796966@yandex.ru, en-5506040@mail.ru \\ ORCID: \\ Kavtarashvili A.Sh. orcid.org/0000-0001-9108-1632 Svitkin V.S. orcid.org/0000-0002-4161-0986 \\ Stefanova I.L. orcid.org/0000-0002-4394-5149 Novotorov E.N. orcid.org/0000-0003-4478-3206 \\ The authors declare no conflict of interests \\ Acknowledgements: \\ Supported by the grant from Russian Science Foundation under project 16-16-04047 for the development of func- \\ tional egg products enriched with essential nutrients, optimal metabolic parameters and low allergenicity \\ Received November 30, 2016
}

\section{Abstract}

The world's market of functional foodstuffs is a permanently growing sector. Functional foods should meet the nutritive requirements of the consumers and render therapeutic and/or preventive effects on human health. Functional eggs enriched with different bioactive substances are one of the most voluminous segments of this market (N. Shapira, 2010). High rate and flexibility of avian lipid metabolism allow fast modifications in egg yolk composition via corresponding alterations in the diets of laying hens. In the last decades nutritionists pay increasingly close attention to $\omega-3$ polyunsaturated fatty acids (PUFAs), primarily $\alpha$-linolenic (ALA, C18:3), eicosapentaenoic (EPA, C20:5), and docosahexaenoic (DHA, C22:6) acids due to the benefits for human health and necessity for brain development, retinal function, prevention of cardiovascular diseases, etc. (A. Simopoulos, 2001); human diets in most countries including Russia are severely deficient in these essential fatty acids. Flexibility of avian lipid metabolism allows transfer of dietary PUFAs into eggs after 1-2 weeks of feeding PUFA-enriched diets (C.O. Leskanich, R.C. Noble, 1997). However, any increase in PUFA contents in dietary lipids can lead to definite changes in lipid metabolism in layers affecting productivity and egg quality: a decrease in blood level of total fat and triacylglycerols, an increase in hepatic level and catabolism of triacylglycerols which can cause the fatty liver hemorrhagic syndrome (FLHS), as well as the decrease in yolk and egg weight (M.E. Van Elswyk, 1997). Another common problem related to egg enrichment with $\omega$-3 PUFAs is fishy taint phenomenon: panel tests often characterize enriched eggs as smelling fish-like, and this effect deteriorates market attractiveness of these eggs (F. Bubel et al., 2011). Diets for laying hens for the production of $\omega-3$ PUFA enriched eggs usually contain one of the three types of dietary PUFA sources. The first is fish oil from different species; its advantages include higher levels of long-chain PUFAs (LC-PUFAs), primarily EPA and DHA, in resulting enriched eggs. Major disadvantages of fish oil, however, are instability of composition and high susceptibility to oxidation; frequent appearance of fishy taint even at the lowest levels of inclusion into the diets; relatively high price, market availability, and contamination with typical oceanic pollutants (I. Fraeye et al., 2012). The second type of additives is flax products, seeds, cake or oil containing substantially lesser amounts of LC-PUFAs compared to fish oil while being extremely rich in ALA (over $50 \%$ of total fatty acids); ALA-enriched lipids in diets, layer body and eggs are more resistant to oxidation. The data of numerous studies suggests that reasonable level of inclusion of flaxseed products into the diets for layers are 5-8\% for seed and cake and $3 \%$ for oil; these doses are reportedly beneficial for productivity and egg quality (E.M. Goldberg et al., 2013). In Russia flax products are available and inexpensive, and can therefore represent the most profitable dietary source of $\omega-3$ PUFA for layers. The third type additives are macro- and microalgal species which are less available and still understudied, though the recent research data show that these additives can be the most promising dietary sources of $\omega-3$ PUFA (J.H. Park et al., 2015). Enrichment of feeds and eggs with $\omega-3$ PUFA requires additional dietary antioxidants to prevent lipid oxidation (Ch. Nimalaratne, J. Wu, 2015); the most efficient and well-studied antioxidant is vitamin $\mathrm{E}$ which is, after that, a valuable bioactive substance per se for egg enrichment. The data of 
different experiments with different $\omega$-3 PUFA sources are often inconsistent and controversial due to the close relation to the multifaceted avian lipid metabolism, and comparative analysis of these studies is further complicated by the lack of estimated parameters; it could be helpful, therefore, to launch an international database related to these experiments and containing raw datasets which could be statistically analyzed and compared in a more efficient way.

Keywords: functional eggs, polyunsaturated fatty acids n-3, lipid metabolism, flax seed and oil, fish oil

The term "functional food product" emerged in recent decades, means a product of everyday consumption that contains certain biologically active substances (BAS) in amounts significantly greater than those in non-functional analogs, and contributes to the improvement of health and (or) prevents the onset and development of diseases [1]. Enrichment of BAS should occur as naturally as possible, since the safety and naturalness of such products are important. In this connection, eggs and poultry meat are of interest because of the high (compared to other farm animals) efficiency of transfer of many substances from feeds to products [2]. In this, it is necessary to ensure both the well-being of livestock when feeding rations enriched with BAS, and the cost and availability of functional products for the population as in retail, they are 15-20\% more expensive than non-functional analogous [1]. Market research (for example, in Serbia) confirmed that this limits demand [3], however, consumption of functional products, including poultry, is expected to increase, as evidenced by the development of production of functional egg in such European countries as Serbia [4]), Macedonia [5] and Greece [6].

This review focuses on the biological and technological aspects of the production of edible egg enriched with various bioactive substances and their complexes.

Functional egg: general statements. By the end of the XX century, it was found that the amount of cholesterol consumed had only a negligible effect on its blood concentration [7], large-scale studies also did not reveal a significant relationship between egg consumption and the risk of cardiovascular disease [8], but "cholesterol disputes" in the press continues [9]. The accumulated data formed the basis for the concept of a functional (enriched, fortified, designer) egg. The first term implies a potential therapeutic and (or) prophylactic effect, the second and third mean directed enrichment with bioactive substances (BAS), the fourth mean the ability to create a product for different population groups and patients in accordance with the needs. The choice of BAS is determined by its deficiency in the human diet, the efficiency of transfer from the feed to the egg, the stability of the content during processing or cooking, the proportion of the daily requirement provided by a single functional egg. So, enrichment with vitamins $B_{1}$ and $B_{2}$ is inexpedient because of their high content in other foods, and for vitamins $\mathrm{A}$ and $\mathrm{C}$ it is impossible due to low transfer to eggs [10].

The lipid composition of the egg is largely determined by the fats in the diet (in contrast to the amino acid which almost does not depend on the diet) [11]. In addition, because of the high metabolic rate of lipids and lipoproteins in chickens, the fatty acid profile of the yolk varies rapidly depending on the diet $[12,13]$, which allows to modify the lipid composition of yolk and enrich it with fat-soluble BAS (for example, vitamin E, carotenoids, polyphenols), as well as selenium and iodine. For different target components of the yolk, the period of transformation and stabilization of the profile is 2-4 weeks [13-15], but the increase in content is noted in a week. This is consistent with the timing of the formation of the egg after the recruitment of the follicle ( 8 days, of which about 7 days accounted for the growth of the follicle before ovulation and about 1 day takes deposition of protein and shell) [16]; about 14 days passes from the onset of the growth of the primordial follicle to the prelaying of the egg [17]. 
The market of functional egg products (yolk, melange, etc.) is also beginning to develop, but in volume it is much inferior to the market of whole eggs [18]. In processing, bioactive substances that are not obtained or disadvantageously introduced into the egg can be added to egg products. In fact, the transfer of vitamin $\mathrm{C}$ and certain micro elements $(\mathrm{Cu}, \mathrm{Zn})$ from feed to eggs is ineffective and does not ensure their sufficient enrichment [10].

$\omega$-3-Polyunsaturated fatty acids. Currently, the fatty acid composition of the diet, especially essential fatty acids (FA), primarily polyunsaturated fatty acids (PUFAs), is receiving increasing attention. Indeed, linoleic PUFA

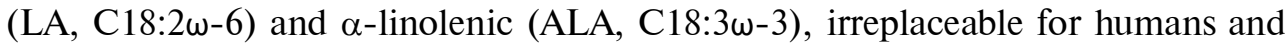
most animals, are not synthesized in the body from more saturated acids due to the lack of $\Delta^{12}$ desaturase [19]. LA and ALA from the diet can serve as precursors in the biosynthesis of PUFAs with longer carbon chains (long-chain PUFAs, LCPUFA). Some physiologically important PUFAs, for example do-

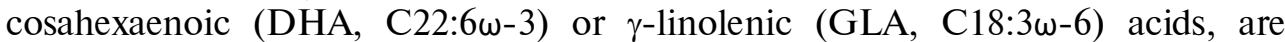
conventionally indispensable, since they are not synthesized at a certain stage of ontogenesis or in some diseases [20, 21].

Physiologically significant PUFAS form $\omega-3$ and $\omega-6$ series (according to the position of the first double bond, counting from the final methyl group). The most important $\omega$-6-PUFAs, in addition to LA, are GLA, long-chain dihomo- $\gamma$ -

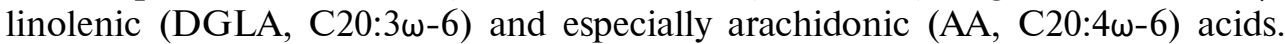
Long-chain DHA and eicosapentaenoic acid (EPA, C20:5w-3) are distinguished in the $\omega-3-$ PUFAs group along with ALA. Physiological and biochemical functions of $\omega-3$ - and $\omega$-6-PUFAs are individual, but competition is possible between them. For example, the use of elongase (elongation FA molecule) and desaturase (can catalyze the appearance of double bonds) in the formation of LCPUFA of both series from the corresponding PUFAs (LA or ALA), as well as in the biosynthesis of eicosanoids (prostaglandins, thromboxanes, prostacyclins, leukotrienes, resolvins, ect), the signaling molecules involved in processes associated with inflammation and other forms of immune response, regulation of cell growth, blood pressure control, etc. Often, the functions of eicosanoids synthesized from the FA series $\omega-3$ and $\omega-6$ are opposite [22], so not only the absolute level, but also the ratio of these acids in the rations are important. For example, with an increase in the fraction of $\omega$-3- PUFAs, the biosynthesis of AA and its derivatives, pro-inflammatory eicosanoids [23], decreases.

As optimal, different ratios of $\omega-6$ and $\omega-3$-PUFAs $(1: 1,3: 1$ and $6: 1)$ are reported [24]. In the countries where the consumption of fish rich in $\omega$-3-PUFAs is traditionally high (for example, in Japan), and the incidence of cardiovascular disease is very low, this ratio is close to $4: 1$ [25]. The 4:1 ratio in the diet leads to a 1:1 ratio in the cell membranes [26]. In developed countries, the indicator for the diet is excessively high reaching from 10:1 to 25:1 [27). Modern diets for poultry based on maize and other grains are also redundant in $\omega-6$-PUFAs (the content of ALA is very small, and DHA and EPA are practically absent) [28]. The vegetable oils used (corn, soybean, sunflower, rapeseed) also contain significant amounts of $\omega$-6-PUFAs (primarily LA) and few $\omega$-3-PUFAs [29], except some rapeseed varieties [30]. Therefore, in the edible egg, the ratio of $\omega-6-$ and $\omega$-3-PUFAs is much higher than the optimal one [31]. It was also noted that in white laying hens, $\omega$-3-PUFAs are deposited more effectively than in brown eggs [32].

To successfully enrich in $\omega$-3-PUFAs, it is required, first, to use a source with their high bioavailability, which does not have a significant negative effect on health, well-being of laying hens, egg production and egg quality, including 
taste and smell; second, to control $\omega-6$ - and $\omega$-3-PUFAs in both the diet and the final product. The problem is also the susceptibility of objects to oxidation with a high proportion of PUFAs (especially with 4-6 double bonds).

In addition, it is important to determine which $\omega-3$ - PUFAs are advisable to enrich the egg. In an adult human, the efficiency of bioconversion of ALA in $\omega$-3-LCPUFA (in DHA and EPA) in the liver is less than $5 \%$; in chickens, it is also low [33, 34], and not only in the liver. Studying in vitro the formation of AA and DHA from ${ }^{14} \mathrm{C}$-labeled LA and ALA (C18) upon incubation with fragments of the yolk sac membrane of the chick embryo, where the activity of $\Delta^{9}$ and $\Delta^{6}$ desaturase was detected [35], the authors expected to reveal the biosynthesis of LCPUFA in transport of yolk lipids through the perivitelline membrane to improve the supply of embryos. However, the bioconversion of both precursors was only 4-8\%, while the main amount of the label after 4 hours was in the fraction of triglycerides and phospholipids of the perivitelline membrane [35].

Intermediate products of conversion of ALA to DHA, the eicosatrienic ETA (C20:3 $\omega-3)$ and docosapentaenic DPA (C22:5 $\omega-3)$ acids, were found in eggs enriched with both ALA and LCPUFA, and of LCPUFA the DHA was most effectively deposited [36]. The high amount of LCPUFA in the diet reduced the effectiveness of bioconversion of ALA to DHA in the liver [36]. The affinity of the $\Delta^{6}$ desaturase to substrate FA was enhanced with an increase in the number of double bonds [37], indicating the advantage of the most unsaturated LCPUFA (EPA, DPA) before ALA in competition for desaturase. Perhaps, therefore, reports of the simultaneous introduction of sources of ALA and LCPUFA (for example, a mixture of flaxseed oil and fish oil) into the diet are few, and their results are not of interest [38]. In a number of studies, the intermediate products of elongation and desaturation of FA were not determined and not taken into account in the total index for $\omega$-3-PUFAs, although, in our opinion, a stepwise assessment of the change in the concentrations of such products would be informative.

Reduction of oxidative stability with increase in the percentage and unsaturation of PUFAs (including $\omega-3$ ) in feeds and liver tissues can lead to the formation of oxidation products harmful for poultry and their transfer to eggs, and in eggs - to a faster lowering quality during storage and/or cooking. J.M. Miranda et al. [39] confirm that the oxidative damage of the yolk is associated only with the direct deposition of oxidized lipids from the diet (from the storage of eggs the lipids do not oxidize), and, however, refer to the paper [40], which shows a decrease in the concentration of substances reacting with thiobarbituric acid (SRTBA, the total concentration of oxidation products of lipids, especially malonic dialdehyde MDA) in eggs after storage for 60 days at $4{ }^{\circ} \mathrm{C}$. The authors of the study [40] believed that the observed effect is most likely due to the reaction of MDA with other egg substances and, possibly, partial polymerization of MDA, which reduces SRTBA. A decrease in SRTBA during storage was reported in other publications [41-43], nevertheless, a steady increase in this indicator was reported as well [44-46]. Thus, the conclusion of J.M. Miranda et al. [39] on the unconditional oxidative stability of yolk lipids in stored eggs is not sufficiently substantiated.

The hypothesis of the transport of oxidized fats from the liver to the yolk has already been advanced [47]. In a number of cases, the values of SRTBA in the liver of layers were increased in response to feeding fish oil [47] or flaxseed [48]. The MDA in a fresh-laid egg in the presence of an antioxidant, the vitamin $\mathrm{E}$, in fodder is also reported [49]. Indeed, the oxidation of yolk lipids is possible, since gas exchange through the shell [50] and the diffusion of water from the protein into the yolk [51] do not cease even at a lower storage temperature. On 
other hands, liquid-phase extraction of lipids for the TBA test can cause oxidation upon solvent distillation, regardless of the presence of antioxidants [52].

The problem of oxidative stability in the enrichment of PUFAS is usually solved with the use of antioxidant stabilizers (selenium, vitamins E and A, carotenoids, etc.), which themselves are valuable BAC for humans and animals and can be added to feed (and, consequently, transferred to eggs). Another recommended technology is to reduce the storage of PUFAs sources and feed the poultry as freshly prepared products as possible with minimal oxidized lipids [53].

In rations, flax (seed or oil) and fish oil of a suitable fatty acid composition as available sources of $\omega$-3-PUFAs [54] are most often used, and marine micro and macro alga have also been proposed. However, with the use of all additives, general (and specific for each) negative consequences for the health of the bird and the quality of eggs are possible.

Changes in the metabolism of lipids and a decrease in the yolk weight in the enrichment with $\omega$-3-PUFAs. This effect was reported by many authors. Thus, in the groups receiving fish oil, the reduction was about $3 \mathrm{~g}$, and it was evaluated as useful, especially for the laying hens post molting [55] because of a decrease in the percentage of large eggs with low quality shells, which in many countries are categorized as low-grade [56]. In other experiments, no decrease was observed. Indeed, on the ration with $3 \%$ linseed oil, the analyzed indicator significantly ( $<<0.05$ ) increased (from 62.88 to $65.28 \mathrm{~g}$ ), and the egg production was slightly below the control [57].

The decrease in yolk weight and blood lipid level in laying hens during prolonged feeding sources of $\omega$-3-PUFAs is possibly associated with changes in fat metabolism. In mammals, an increase in the proportion of $\omega-3$ PUFAs in the diet leads to suppression of lipid biosynthesis in the liver, enhancement of their $\beta$-oxidation in peroxisomes, and subsequent reduction in blood lipids of different fractions [58]. Poultry also had lipid lowering (a reduction in the amount of total fat and triglycerides in the blood) when feeding flaxseed [59] or fish oil [55, 60]. Later this hypothesis received a nutrigenomic confirmation. Cod-liver oil as a source of LCPUFA caused an increase in the expression of transcription factors involved in the biosynthesis and catabolism of FA in the liver, namely of the $\alpha$ type receptor activated by peroxisome proliferators (PPAR $\alpha$ ), and the sterol regulatory element-binding proteins (SREBPs) [61], leading to lipid lowering and liver lipidosis. Another hypothesis [62] linked the regulation of observed changes in fat metabolism with the effect of endogenous estradiol, although the mechanism of such influence remained unclear for the authors. A hypothesis based on the effect of flax phytoestrogens on laying hens is partly associated with this assumption [63]. In mammals, phytoestrogens (secoisolariciresinol diglycoside and matairesinol) are metabolized by the microflora of the large intestine with production of mammalian lignans, the enterodiol and enterolactone, that exhibit estrogenic and anti-estrogenic effects due to structural similarity to endogenous estrogens [64]. In pullets who received flaxseed, these lignan metabolites were also detected and blood estradiol concentration decreased (up to -30\%) [65]. Perhaps this is why, when feeding flaxseed, egg production is reduced only at the beginning of oviposition, as the hormonal balance and lipid metabolism are not yet fully adapted to the requirements of laying and are particularly sensitive to any effects. Besides, using aminoglutethimide to suppress the biosynthesis of estradiol, it has long been shown that blood estradiol concentration affects the weight of eggs and yolk rather than egg production [66], which, with long-term feeding of flaxseed, generally remains lower compared to control.

Metabolic syndrome of liver fatness. Fatty liver hemorrhagic syndrome (FLHS) observed in laying hens at high energy rations is characterized by 
a high level of different lipid fractions, especially triglycerides, increased fatty infiltration of hepatocytes, hemorrhages with consequences up to lethal. The etiology of the syndrome is not fully understood, although it is known that in birds predisposition to this is related to the fact that birds (unlike mammals) de novo FA biosynthesis occurs only in the liver, so the chylomicrons formed in the intestine are absorbed directly into the portal vein and practically do not enter other tissues [67]. Factors influencing the manifestation of this syndrome in laying hens are housing, genotype, diet composition, hormonal and antioxidant statuses [68]. The relationship between FLHS and the level of $\omega$-3-PUFAs in the diet of laying hens [69-71] can not be considered clearly established, since such a relationship was not found in other studies either in visual assessment of liver status and hemorrhage index [48, 72] or in histological studies [59]. The available data indicate rather a relationship between the manifestation of FLHS and the amount of total triglycerides (regardless of their fatty acid profile) [73, 74].

"Fishy" smell of eggs. The appearance of eggs, which smell like stale fish, is associated with the inclusion in the diet of not only fish products, but also, for example, flax or rape oil or oilcakes. The unpleasant smell substantially reduces the demand for $\omega$-3-PUFAs enriched eggs and egg products [54]. However, the organoleptic properties do not clarify either the chemical nature of the substances that cause the smell, or the cause of its appearance. A tasting assessment is more a marketing one than a biological or technological indicator that reflects changes that may or may not be related to PUFAs. Trimethylamine (TMA), which along with bioamines (putrescine, cadaverine, etc.) is released when the fish products are naturally spoiled, are the only well-studied substance that causes a truly fishy smell of eggs [75]. TMA is a product of some microorganisms of the distal part of the small intestine (including cecums) in chickens [76]. There are chicken genotypes predisposed to fishy smell of eggs due to the high frequency of A-T single-nucleotide polymorphism in exon 7 of FMO3 (flavin-containing monooxygenase 3) gene; interestingly, this recessive mutation is found almost exclusively in brown laying hens [77]. In humans and cattle, this mutation causes trimethylaminuria, i.e. a fishy smell of breathing and (or) the human body or milk of cows. Due to this mutation, the liver shows complete or partial deficiency in TMA oxidase, necessary for TMA oxidation to almost odorless and non-volatile TMA-N-oxide (TMAO). As a result, in chickens TMA secreted by intestinal bacteria is not oxidized in the liver to the $\mathrm{N}$-oxide and is not excreted by the kidneys, which occurs normally, but accumulates in the ovarian follicles. Expression and heritability of the mutation is enhanced by prolonged diets with high proportion (12-24\%) of rapeseed oilcake acting as a nutriogenetic trigger, in this, choline, the main precursor in bacterial synthesis, unlike rapeseed, does not affect the deposition of TMA in the egg [78]. The observed nutriogenetic effect is explained by the action of the anti-nutrient factors of rapeseed glucosinolates that inhibit the expression of hepatic TMA oxidase and are also present (however, in much smaller amounts) in flaxseed. However, in none of the studies TMA has yet been identified as the main cause of fishy smell. It was reported that in hens with trimethylaminuria, breathing often have this smell [76], but this fact has not been noted in papers reporting findings in enriching eggs with PUFAS.

Thus, in most cases, for the time being, only the connection of the fish smell of eggs with the products of oxidation of PUFAs-rich lipids is assumed, and the presence of antioxidants does not always eliminate the problem. Earlier it was reported that fish oil in the laying hen's diet affects the content of 23 out of the 42 volatiles studied in the egg, and the possibility was discussed of the appearance of a fishy smell as a sensory resultant of quantitative change of several of these substances [79]. The appearance of fish smell in milk fat during oxidation is specifi- 
cally associated with volatile compounds of aldoketone nature with conjugated diene fragments in hydrocarbon chains [80]. Similar compounds, for example 2,4-heptadiental, are found among products of spontaneous oxidation of fish oil during storage, and the authors also identify their smell as "fishy" [81]. Theoretically, the oxidation of PUFAS (and to a greater extent, LCPUFA) can give similar compounds and may be associated with biochemical mechanisms of fish egg odor, but this phenomenon and the development of countermeasures require special studies.

We note that only a very small number of papers contain a complex of such indicators as the fatty acid composition of sources and rations, the content of all target FA in blood, liver and eggs, the ratio of $\omega-6-$ and $\omega-3-$ PUFAs, organoleptic evaluation, etc., so the results, which are often contradictory, are difficult to compare. Data on the productivity of layers is also ambiguous. Therefore, it would be useful to create an international database of experimental data, which allows us to conduct statistical studies of information files.

Sources of $\omega$-3- PUFAs in rations of laying hens. Cod-liver oil. This is the first and most studied target source of $\omega$-3-PUFAS. Its main disadvantages are instability of composition, including that due to high oxidation ability, which is accompanied by a fishy smell of eggs and meat. The problem is overcome only partially, which has led to interest in the study of flax as an alternative source of less unsaturated lipids [82].

As the used additive, the fat from the American herring, menhaden (Brevoortia tyrannus), prevails. However, it is known that, due to instability in species composition of the catch, seasonal fluctuations in fish condition, high predisposition to oxidation due to a significant share of LCPUFA with a large number of double bonds (EPA, DHA), the composition of fish products (fat and flour) differs markedly not only between species of fish but also between batches from one supplier [83]. In Australia, a number of commercial fish oil preparations (even encapsulated ones) turned out to be highly oxidized (the concentration of oxidation markers exceeded the permissible levels), only 2 of 32 samples examined EPA and DHA met the specifications, and in the rest were lower than those declared by the manufacturers [84].

The next and main disadvantage of fish oil, even at low dosages, is fishy smell of eggs [82]. The deodorization of the additive did not improve the organoleptic characteristics of eggs, e.g. 2, 4 or $6 \%$ of dietary fish oil led to significantly higher scores on the analyzed index, and no significant differences were found between the deodorized and non-deodorized forms [85]. At that, as in many other works, a significant $(\mathrm{p}<0.05)$ linear decrease in the weight of eggs with an increase in the dose of dietary fish oil (by 3-4\% at a dose of $6 \%$ ) was noted. The use of deodorized fish oil significantly increased the deposition of the sum of $\omega$-3PUFAS in eggs (343 against $246 \mathrm{mg} /$ yolk at doses of $6 \%$ against $53 \mathrm{mg} /$ yolk in the control). Perhaps, deodorized fat is more attractive for laying hens (the consumption of feed in such groups is 105 versus $101 \mathrm{~g} \cdot$ head $^{-1} \cdot$ day $\left.^{-1}\right)$, which leads to a difference in the sum of $\omega$-3- PUFAs in rations $(17.82$ and $15.88 \mathrm{~g} / \mathrm{kg}$ vs. $2.39 \mathrm{~g} / \mathrm{kg}$ in the control). Encapsulation of fish oil also does not exclude the appearance of a fishy smell. In White Leghorns, of 2, 4 or $6 \%$ of dietary microencapsulated fish oil tested, even a $2 \%$ dose significantly worsened the odor in 3 weeks compared to the control, although the total amount of $\omega$-3-PUFAs significantly and linearly increased from 141 for control to $299 \mathrm{mg} /$ yolk for $6 \%$ of fish oil [86]. Do not forget that deodorization or microencapsulation of fish oil significantly increases the cost of the feed additive.

Finally, fish oil is produced mainly from commercial fish, whose stocks are falling in many countries, and additionally, contamination with heavy met- 
als, polychlorinated biphenyls and other hazardous pollutants is increasing [87]. This leads to a reduction in market availability and a rise in the cost of quality fish oil for feed production.

Importantly, the data on the effectiveness of fish oil application are ambiguous. Thus, when $1.5 \%$ of fish oil was added to laying hen ration, their productivity and the main quality parameters of eggs were kept within control limits [88]. In other experiments, with a fish oil dose of $3 \%$, the chick's productivity did not change, but the sum of $\omega$-6-PUFAs decreased reliably $(\mathrm{p}<0.05)$, the amount of DHA and EPA increased (from 0.19 to $3.21 \%$ and from 0.00 to $0.18 \%$, respectively), and $\omega-6-P U F A s / \omega-3-P U F A s$ ratio decreased from 33.52 to 2.55 compared to the control eggs [89]. It is now recognized that the proportion of fish oil in the diet for enriching eggs with $\omega$-3-PUFAs should not exceed $1.5 \%$ [90]. The same is confirmed for cod-liver oil. In ducks, 5-6\% of dietary oil led to a significant and reliable increase in the scores of eggs for fishy smell, but at a smaller dosage (2-4\%), this was not noted. Productivity of ducks remained within control, except for a small decrease in egg weight at $6 \%$ dose [91].

Flaxseed oil and seed. More than half of FA in the flaxseed lipids is in ALA, and as a source, flaxseed has no equal [92]. Due to the lack of availability in the market and the relatively high price, the flaxseed oil are used less often in feeding birds than seeds or oilcakes [93]. The whole seed contains about $40 \%$ fat, 20-25\% protein and 3-10\% sticky substances; the latter, along with the lignan phytoestrogens, linatinum (pyridoxine antagonist) and linamarin (cyanogenic glucoside), are among the main anti-nutrient factors of flax [94]. Producers usually recommend flax seeds as an additive to adult fodder at a dose not more than $10 \%$ [93] and processed seeds after grinding, autoclaving, granulation, extrusion, microwave heat treatment, etc., which increases the availability of protein and $\omega$-3-PUFAs [95, 96]. When feeding small gravel or shells, the bird very effectively grinds whole seeds in the muscular stomach [97].

The water-soluble seed adhesives, consisting mainly of neutral arabinoxylans and acidic pectin-like fractions, which are contained primarily in seed coats, can, like phytoestrogens, adversely affect productive parameters in laying hens. Arabinoxylans can significantly increase the viscosity of chyme, reducing the effectiveness of dietary nutrients [98]. It is known that the content of nonstarch polysaccharides in linseed is higher than in rapeseed [99], and rations with rapeseed should be enriched with the enzymes that decompose non-starch polysaccharides [100]. Unfortunately, there are few such studies on flax, and they are not mentioned in the literature on egg enrichment with $\omega$-3-PUFAs. However, it was reported that when feeding $15 \%$ of linseed to laying hens from 39 to 63 days of age, the enrichment of the ration with the multi-enzyme Superzyme ${ }^{\circledR}-\mathrm{OM}$ complex (Canadian Bio-Systems Inc., Canada) that cleaved non-starch polysaccharides significantly improved egg production (from 78.0 to $80.9 \%$, p $<0.01$ ) and feed conversion (from 2.15 to $2.03 \mathrm{~kg} / \mathrm{kg}, \mathrm{p}<0.001$ ), while feeding the same dose of flaxseed without the enzyme reduced the egg production and shell weight compared to control without flax and the enzyme. When using the enzyme, a significant $(\mathrm{p}<0.01)$ increase was recorded in total $\omega$-3-PUFAs (from 546 to 578 $\mathrm{mg}$ per egg for an egg weight of $60 \mathrm{~g}$ ) and in DHA (from 91.8 to $101.9 \mathrm{mg}$ ) [101]. It is not excluded that multi-enzyme additives in combination with high flaxseed ratio can improve production of eggs enriched with $\omega$-3-LCPUFA, but so far the question of the organoleptic qualities of such a product remains open.

It is estimated that for every $1 \%$ of dietary flaxseed, $\omega$-3-PUFAs amount increases by about $40 \mathrm{mg} / \mathrm{egg}$ [102]. High doses of flaxseed can increase ALA up to $200 \mathrm{mg} / \mathrm{egg}$, DHA up to $90 \mathrm{mg} / \mathrm{egg}$ [90]. Consequently, it is practically advisable a dosage of no more than $5 \%$ for flaxseed and no more than $3 \%$ for oil, because at 
lower doses, the content of the target FA in the egg will be insufficient, whereas larger ones can adversely affect layer productivity and egg quality in the absence of a noticeable increase in total $\omega$-3-PUFAs, since the plateau has already been reached [103]. A limit flaxseed dose of $8 \%$ established in the 1990s [104] currently seems too high (due to the impact on productivity and fishy smell). According to most researchers, in moderate amounts flaxseed does not affect the egg production, except early productive period [69].

Comparing the effect of a standard diet rich in $\omega$-6-PUFAs (especially LA) and the same diet enriched with ALA by adding $5 \%$ of the extruded flaxseed, it was found [105] that total $\omega$-3-PUFAs in the egg was 3.8 times higher than in the control (258.2 vs. $67.3 \mathrm{mg} / \mathrm{egg}$ ), ALA was 6.4 times higher (156.7 vs. $24.5 \mathrm{mg} / \mathrm{egg}$ ), and DHA was 2.4 times higher (101.6 vs. $42.8 \mathrm{mg} / \mathrm{egg}$ ). A 3.6fold decrease in $\omega$-6-PUFAs/ $\omega$-3-PUFAs, a 5.7-fold decrease in LA:ALK, and 3.0-fold decrease in AA:DHA were also noted. After a week diet enriched with ALA, total $\omega$-3-PUFAs increased 3.4-fold, being in 3 and 5 weeks 3.7 times and 4.0 times higher, respectively, compared to control. In introduction of $0,5,10$, 15 and $20 \%$ of unroasted or roasted dietary full-fat flaxseed [106], it was found that unroasted seeds declined egg production in chickens while the best (although unreliable) egg-laying rates were noted in groups receiving 5 or $10 \%$ of roasted seeds (93.82 and $93.35 \%$ vs. $92.71 \%$ in the control). The weight and color of the yolk remained in all groups within the control indicators. The PUFAs content reached a plateau at doses of both additives of $15 \%$, with 2.9fold increase for DHA, 4.0-fold increase for DPA, 5.5-fold increase for EPA, and 9.8-fold increase for ALA, and not $10 \%$ reported in other works. The authors attribute this to the unusually low proportion of ALA (38.43\% of FA) in the flaxseed used and note that the flaxseed roasting did not significantly improve the deposition of PUFAs in the egg. Study of the rations with linseed oil $(1.5,3.0$ and $4.5 \%)$ [107] showed that its use at a dose of $3 \%$ instead of corn, soybean meal and fish meal increased the deposition of $\omega-3-$ and $\omega-6-$ LC 2.54 times $(0.2 \mathrm{mg} / \mathrm{ml}$ egg volume). ALA increased 1.55 times, EPA increased 0.15 times, docosapentaenic acid (C22:5) concentration increased 1.6 times, and DHA was 3.22 times higher. The protein quality (Haugh units) in the group with $3.0 \%$ of dietary linseed oil was $81.3 \%$ and was higher than in other groups, i.e. $80.8 \%$ for the control and $4.5 \%$ oil, and $80.0 \%$ for $1.5 \%$ oil (interest in the quality of the protein is not completely understandable).

Of the beneficial effects of dietary flaxseed, it should be noted the increase in IgY concentration in eggs: when feeding $10 \%$ of linseed oilcake, it significantly $(\mathrm{p}<0.05)$ increased from 10.4 to $12.0 \mathrm{mg} / \mathrm{g}$ yolk [108]. In this experiment, the egg production was significantly $(\mathrm{p}<0.05)$ higher than in control, however, the egg weigh, relative shell weight $(\%)$ and shell thickness decreased with the same reliability. Recently, an increase in the counts of useful lactobacilli in the intestines of layers that received 0.5 or $1.0 \%$ linseed oil was also reported [109].

Water plants. Alternative sea sources of $\omega$-3-PUFAs attract researchers, since some auto- and heterotrophic micro-algae produce quite significant amounts of these FA, primarily EPA and DHA. The fatty acid profile in a number of species Phaeodactylum and Nannochloropsis (produce EPA up to $40 \%$ of total FA), Thraustochytrium and Schizochytrium (synthesize significant amounts of DHA up to 30-40 \% of FA), as well as some Chlorella species (produce significant amount of ALA) [110] are most studied. In aquaculture, it is possible to increase the FA deposition, including targeted ones, by controlling the composition of the growth media and conditions [111]. Water plants are a valuable source of protein for farm animals [112]. In addition, significant quantities of oily substances remained as a by-product after PUFAs extraction from algae 
could be used in production of diesel biofuels [113]. Another important advantage of algae as a component of animal feed, including laying hens, is the high content of natural carotenoids ( $\beta$-carotene, canthaxanthin, astaxanthin, etc.). In laying hens, they improve yolk color and antioxidant status of eggs [114]. Algae contain various trace elements, but the effectiveness of algae as dietary source of trace elements for poultry and the influence on the mineralization of egg shell have not been practically studied [115]). When feeding algae Schyzochytrium $(0.5 \%$ and $1.0 \%$ ) from week 40 of life for the next 6 weeks [115], the egg production approximated the control, and the quality of the shell and the color of the yolk improved. The blood triglycerides and total cholesterol significantly decreased in both experimental groups, DHA concentration in the eggs significantly increased (from $0.70 \%$ in the control to 0.75 and $0.88 \%$ for two doses of the additive), and $\omega$-6-PUFAs/ $\omega$-3-PUFAs value significantly decreased (from 11.36 in the control to 8.20 and 6.08 ).

It turned out that the use of algae as a dietary source of $\omega$-3-PUFAs is also associated with the problem of fishy smell. When comparing flaxseed and powdered dried algae Nannochloropsis oculata at equal dosages (8\%), it was found [116] that DHA level $(111.62 \mathrm{mg} / \mathrm{egg})$ was significantly $(\mathrm{p}<0.05)$ higher for the algae than for flaxseed (98.66 mg/egg). However, with an organoleptic evaluation of boiled eggs, the scores for fishy smell, hardness and elasticity of egg yolk in the control were significantly better than in both test groups $(\mathrm{P}<0.001, \mathrm{P}<0.01$ and $\mathrm{P}<0.001$, respectively), and more than half of the tasters preferred eggs from the control poultry.

Enrichment of eggs with $\omega$-3-PUFAs to a large extent depends on the species of algae. It was reported that at 5 or $10 \%$ of dietary dried biomass Nannochloropsis gaditana, the accumulation of $\omega$-3-PUFAs (especially EPA) in the egg was low [117]. But in another study [118], when feeding the preparation of dehydrated whole-cell algae (All-G-Rich, Alltech, USA) for 70 weeks of the productive period, the DHA concentration in eggs linearly and significantly ( $p<$ $0.05)$ increased as the dosage grew $(85,187$ and $240 \mathrm{mg} / 100 \mathrm{~g}$ for the groups receiving 0,1 and $2 \%$ additives). There were no influence of algae on the intensity of egg production $(84 \%)$, the egg weight $(61.5 \mathrm{~g})$, feed conversion $(1.59 \mathrm{~kg}$ per 12 eggs), egg shell weight (9.9\% of the egg weight) and strength. In general, studies on the use of algae as a source of $\omega$-3-PUFAs in egg enrichment have yielded rather encouraging results. Possibly, over time algae will become more important as a component of feed, including that in Russia, but so far the availability of these additives is limited.

The effectiveness of stabilizing $\omega$-3-PUFAs with antioxidants. It is known that dietary $\omega$-3-PUFAs together with antioxidants promotes oxidative stabilization of lipids in the liver, meat, and egg yolk. This method allows to avoid fishy smell, although in some cases not effectively enough, especially when using fish oil [63]. In the eggs, various natural and synthetic compounds and their mixtures, carotenoids, flavone and benzoquinolone antioxidants, vitamins $\mathrm{C}$, A and E, selenium, iodine, gallates, butylated hydroxyanisole and hydroxyltoluol etc. were tried as antioxidants [119].

The most effective stabilizer of yolk lipids, enriched with $\omega$-3-PUFAs, is fat-soluble vitamin E. Its antioxidant properties are associated with the ability to block lipid peroxidation by binding radicals of fatty acid hydroperoxides due to the formation of ether in phenolic groups and delocalization of the electron density along the aromatic structure of the vitamin fragment of the ether molecule [120]. When comparing the role of different doses of vitamin $E$ ( $\alpha$-tocopherol, 0, 50, 100 and $150 \mathrm{IU} / \mathrm{kg}$ feed) and butylated hydroxytoluol (BHT, 0, 50, 100 and $150 \mathrm{mg} / \mathrm{kg}$ feed) in rations with $10 \%$ flaxseed [40], vitamin $\mathrm{E}$ in all the doses, except for the lowest one, more effectively maintained the $\omega$-3-PUFAs 
concentration in eggs stored at $4{ }^{\circ} \mathrm{C}$. At $50 \mathrm{IU} / \mathrm{kg}$ vitamin $\mathrm{E}$ and BHT doses of $50-100 \mathrm{mg} / \mathrm{kg}$, the $\omega-3$-PUFAs in eggs decreased by $13-17 \%$. It should be noted that egg concentration of vitamin E during storage also decreased. A relationship between productivity of the layers and the dose of dietary vitamin E was reported. With an increase in the latter from 27 to $50 \mathrm{IU}$, the egg production significantly ( $\mathrm{p}<0.05$ ) increased from 94.3 to $96.1 \%$ [53]. The addition of vitamin $\mathrm{E}$ at $100 \mathrm{IU} / \mathrm{kg}$ to a diet with $10 \%$ flaxseed significantly $(\mathrm{p}<0.05)$ increased the rate of SRTBA in liver of the chickens compared to those fed with flaxseed without vitamin E, providing SRTBA within the control values in the birds fed neither flaxseed nor vitamin E [59].

Interesting results were obtained in the study of accelerated oxidation of PUFAs in vitro [121], when the stability of ALA and DHA was evaluated in the presence of different doses of $\alpha$-tocopherol $(0.0,0.25,2.5$ and $5.0 \mathrm{mg} / \mathrm{mg}$ of FA) at $70{ }^{\circ} \mathrm{C}$. In the absence of vitamin E, DHA concentration decreased after 24 hours of incubation to $78.2 \%$, after 72 hours - to $43.0 \%$ of the initial value, for ALA the indicators were 89.2 and $52.6 \%$, respectively. All the investigated doses of vitamin E increased the safety of both FA compared to the control without the vitamin, but the improvement was not as clear as could be expected, as in the experiment, unlike natural conditions, vitamin E could not restore its activity after neutralizing the oxidized FA. Thus, after 24 hour incubation, the best protection for DHA was observed at 2.5 and $5.0 \mathrm{mg} / \mathrm{mg}$ vitamin E (87.4 and $87.9 \%$ ), for ALA the doses were 0.25 and $2.5 \mathrm{mg} / \mathrm{mg}(99.1 \%$ and $98.1 \%)$, whereas $5.0 \mathrm{mg} / \mathrm{mg}$ vitamin E resulted in the percentage for ALA close to that in the control (only 90.4\%). After 72 hour incubation, the highest DHA protection with vitamin E was at 0.25 and $2.5 \mathrm{mg} / \mathrm{mg}(79.6$ and $62.5 \%)$, and the maximum dose $(5 \mathrm{mg} / \mathrm{mg})$ provided only $55.9 \%$ protection. For ALA, the lowest dose of vitamin E was also more effective $(94.2 \%$ at $0.25 \mathrm{mg} / \mathrm{mg}$ and $87.4 \%$ at 2.5 $\mathrm{mg} / \mathrm{mg}$ ), and at the highest dose, ALA protection did not exceed $77.0 \%$. These data reflect a non-linear relationship between vitamin $\mathrm{E}$ concentration and PUFAs stabilization (up to a decrease in stabilization of high PUFAs lipids under an excess of vitamin E), as well as a significantly higher oxidative stability of ALA in contrast to DHA.

Thus, enriching the diet of layers with sources of $\omega$-3-polyunsaturated fatty acids (PUFAs) to increase their content in a functional egg can lead to hypolipidemia, lipidosis, a decrease in yolk weight and appearance of fishy smell. Additives based on fat of oily fish do not provide oxidative stability of long-chain (LC) PUFAs in feed, poultry and eggs, fishy smell often appears in products, and the availability and environmental safety of such additives are low. Flaxseed, oilcake and oil products are inferior because of anti-nutrients and low (compared to fish oil) LCPUFA deposition in eggs, but these additives are cheaper and more available, can provide higher oxidative stability of lipids, and caused less fishy smell of eggs. The micro-algae rich in PUFAs are perhaps physiologically optimal, but not universally available and insufficiently studied supplements. Long-term research allows to recommend maximum dietary dose in laying hen feeds of $1.5-2.0 \%$ for fish oil, 5-8 \% for flax seed or oilcake, $3 \%$ for flax oil. An increase in the dosage can reduce productivity in laying hens. Enrichment with $\omega$-3-PUFAs, which reduces oxidative stability of egg lipids, requires additional dietary antioxidants, of which vitamin $\mathrm{E}$ is most popular.

\section{REFERENCES}

1. S i ry I., Ká polna E., Kápolna B., Lugas i A. Functional food. Product development, marketing and consumer acceptance - A review. Appetite, 2008, 51: 456-467 (doi: 
10.1016/j.appet.2008.05.060).

2. F i s i n i n V.I. Ptitsevodstvo Rossii - strategiya innovatsionnogo razvitiya [Poultry farming in Russia - innovative strategy]. Moscow, 2009 (in Russ.).

3. Rodić V., Perić L., Pavlovski Z., Vlahović B. Consumers' perception and attitudes towards table eggs from different housing systems: the case study from Serbia. Proc. XIII European Poultry Conf., Tour, France, August 23-27, 2010 (CD).

4. Rodić V., Rodić V., Milošević N. Production of poultry meat and eggs as functional food - Challenges and opportunities. Biotechnol. Anim. Husbandry, 2011, 11(3): 511-520 (doi: 10.2298/BAH1103511P).

5. Gjorgovska N., Filev K. Multi-enriched eggs with omega 3 fatty acids, vitamin E and selenium. Arch. Zootech., 2011, 14(2): 28-35.

6. Yannakopoulos A., Tserveni-Gousi A., Christaki E. Enhanced egg production in practice: The case of bio-omega-3 eggs. International Journal of Poultry Science, 2005, 4(8): 531-535 (doi: 10.3923/ijps.2005.531.535).

7. Howell W.H., Mc Namara D.J., Tosca M.A., Smith B.T., Gaines J.A. Plasma lipid and lipoprotein responses to dietary fat and cholesterol - A meta-analysis. Am. J. Clin. Nutr., 1997, 65(6): 1747-1764.

8. Hu F.B., Stampfer M.J., Rimm E.B., Manson J.E., Ascherio A., Coldit z G.A., Rosne r B.A., S p i ege $1 \mathrm{man}$ D., S peizer F.E., S a cks F.M., He n$\mathrm{n}$ e ke n s C.H., Will e t W.C. A prospective study of egg consumption and risk of cardiovascular disease in men and women. JAMA-J. Am. Med. Assoc., 1999, 281(15): 1387-1394.

9. Gray J., Griffin B.A. Eggs and dietary cholesterol - dispelling the myth. Nutr. Bull., 2009, 34(1): 66-70 (doi: 10.1111/j.1467-3010.2008.01735.x).

10. S u r a i P. Kombikorma, 2010, 6: 95-96 (in Russ.).

11. Cruickshank E.M. Studies on the fat metabolism in the fowl. I. The composition of the egg fat and depot fat of the fowl has affected by the ingestion of large amounts of different fats. Biochem. J., 1934, 28: 965-977.

12. A r k h i p o v A.V. Lipidnoe pitanie, produktivnost' ptitsy i kachestvo produktov ptitsevodstva [Lipid nutrition, poultry productivity and quality of poultry products]. Moscow, 2007 (in Russ.).

13. Lesk a n i ch C.O., N oble R.C. Manipulation of the $n$-3 polyunsaturated fatty acid composition of avian eggs and meat. World's Poultry Sci. J., 1997, 53(2): 155-183 (doi: 10.1079/WPS19970015).

14. Griminge r P. Lipid metabolism. In: Avian Physiology. P.D. Sturkey (ed.). Springer, NY, 1986: 345-358.

15. H a rg is P.S., Van E $1 \mathrm{~s}$ w y k M.E., H a rg is B.M. Dietary modification of yolk lipid with menhaden oil. Poultry Sci., 1991, 70(4): 874-883 (doi: 10.3382/ps.0700874).

16. Lovell T.M., Gladwell R.T., Groome N.P., Knight P.G. Ovarian follicle development in the laying hen is accompanied by divergent changes in inhibin A, inhibin B, activin A and follistatin production in granulosa and theca layers. J. Endocrinol., 2003, 177(1): 45-55 (doi: $10.1677 /$ joe.0.1770045).

17. Perry M.M., Waddington D., Gilbert A.B., Hardie M.A. Growth rates of the small yolky follicles in the ovary of the domestic fowl. IRCS Med. Sci.-Biochem., 1983, 11: 979-980.

18. Kassis N., Drake S.R., B e a mer S.K., Matak K.E., Jaczynski J. Development of nutraceutical egg products with omega-3-rich oils. LWT - Food Science and Technology, 2010, 43(5): 777-783 (doi: 10.1016/j.lwt.2009.12.014).

19. Ganesan B., B rothersen C., M c Mahon D.J. Fortification of foods with omega-3 polyunsaturated fatty acids. Critical Reviews in Food Science and Nutrition, 2014, 54(1): 98-114 (doi: 10.1080/10408398.2011.578221).

20. Swanson D., B 1ock R., Mousa Sh.A. Omega-3 fatty acids EPA and DHA: Health benefits throughout life. Adv. Nutr., 2012, 3(1): 1-7 (doi: 10.3945/an.111.000893).

21. K a p o o r R., H u a ng Y.S. Gamma linolenic acid: an antiinflammatory omega-6 fatty acid. Curr. Pharm. Biotechnol., 2006, 7(6): 531-534 (doi: 10.2174/138920106779116874).

22. Simopoulos A. Evolutionary aspects of diet and essential fatty acids. World Rev. Nutr. Diet., 2001, 88: 18-27 (doi: 10.1159/000059742).

23. Li D., $\mathrm{Hu}$ X. Fish and its multiple human health effects in times of threat to sustainability and affordability: are there alternatives? Asia Pac. J. Clin. Nutr., 2009, 18(4): 553-563 (doi: 10.6133/apjcn.2009.18.4.15).

24. S t o 11 A. The omega-3 connection. Simon and Schuster, NY, 2001: 40.

25. A b edi E., S a h a ri M.A. Long-chain polyunsaturated fatty acid sources and evaluation of their nutritional and functional properties. Food Sci. Nutr., 2014, 2(5): 443-463 (doi: $10.1002 / \mathrm{fsn} 3.121)$.

26. A $11 \mathrm{p}$ o $\mathrm{rt} \mathrm{S}$. The queen of fats: why omega-3 fats were removed from the western diet and what we can do to replace them. University of California Press, Berkeley, 2007: 115.

27. S imopoulos A.P. The importance of the ratio of omega-6/omega-3 essential fatty acids. Biomed. Pharmacother., 2002, 56(8): 365-379 (doi: 10.1016/S0753-3322(02)00253-6).

28. S p a rk s N.H.C. The hen's egg - is its role in human nutrition changing? World's Poultry Sci. J., 2006, 62(2): 308-313 (doi: 10.1079/WPS200599).

29. O k ol e lova T.M. Ptitsevodstvo, 2013, 5: 15-19 (in Russ.). 
30. Antongiovanni M., Minieri S., Buccioni A., Galligani I., Rapaccini S. Transfer of dietary fatty acid from butyric acid fortified canola oil into the meat of broiler. Ital. J. Anim. Sci., 2009, 8(Suppl. 2): 754-756 (doi: 10.4081/ijas.2009.s2.754).

31. S ha pi r a N. Every egg may have a targeted purpose: Toward a differential approach to egg according to composition and functional effect. World's Poultry Sci. J., 2010, 66(2): 271-284 (doi: 10.1017/S0043933910000322).

32. At a las M.S., C it i 1 O.B. Comparison of fatty acid composition of egg yolks obtained white and brown hens fed in the same way method. Maced. J. Anim. Sci., 2013, 3(1): 41-44.

33. Ko m p rada T. Eicosapentaenoic and docosahexaenoic acids as inflammation-modulating and lipid homeostasis influencing nutraceuticals: A review. Journal of Functional Foods, 2012, 4(1): 25-38 (doi: 10.1016/j.jff.2011.10.008).

34. Plourde M., Cunnane S.C. Extremely limited synthesis of long chain polyunsaturates in adults: implications for their dietary essentiality and use as supplements. Applied Physiology, $\mathrm{Nu}$ trition, and Metabolism, 2007, 32(4): 619-634 (doi: 10.1139/H07-034).

35. S pe ake B.K., De a ns E.A. Biosynthesis of oleic, arachidonic and docosahexaenic acids from their $\mathrm{C} 18$ precursors in the yolk sac membrane of the avian embryo. Comp. Biochem. Physiol. B Biochem. Mol. Biol., 2004, 138(4): 407-414 (doi: 10.1016/j.cbpc.2004.05.006).

36. Calchadora P., García-Rebollar P., Alvarez C., Méndez J., De B las J.C. Double enrichment of chicken eggs with conjugated linoleic acid and n-3 fatty acids through dietary fat supplementation. Anim. Feed Sci. Tech., 2008, 144(3-4): 315-326 (doi: 10.1016/j.anifeedsci.2007.10.010).

37. S a rd e s a i V.M. Nutritional role of polyunsaturated fatty acids. J. Nutr. Biochem., 1992, 3(4): 154-166 (doi: 10.1016/0955-2863(92)90110-5).

38. García-Rebollar P., Cachaldora P., Alvarez C., De Blas C., Méndez J. Effect of the combined supplementation of diets with increasing levels of fish and linseed oils on yolk fat composition and sensorial quality of eggs in laying hens. Anim. Feed Sci. Tech., 2008, 140(3-4): 337-348 (doi: 10.1016/j.anifeedsci.2007.03.006).

39. Miranda J.M., Anton X., Redondo-Valbuena C., Roca-Saavedra P., Rodriguez J.A., Lam as A., Franco C.M., Cepeda A. Egg and egg-derived products: Effects on human health and use as functional foods. Nutrients, 2015, 7(1): 706-729 (doi: 10.3390/nu7010706).

40. H a y at Z., Cheria n G., P a sha T.N., Khat t a k F.M., J abbar M.A. Oxidative stability and lipid components of eggs from flax-fed hens: Effect of dietary antioxidants and storage. Poultry Sci., 2010, 89(6): 1285-1292 (doi: 10.3382/ps.2009-00256).

41. Galobart J., Barroeta A.C., Bauce $11 \mathrm{~s}$ M.D., Cortinas L., Guardiola F. Tocopherol transfer efficiency and lipid oxidation in fresh and spray-dried eggs enriched with n3 polyunsaturated fatty acids. Poultry Sci., 2001, 80(10): 1496-1505 (doi: 10.1093/ps/80.10.1496).

42. Gebert S., Messikommer R., Pfirter H.P., B e e G., We nk C. Dietary fats and vitamin $\mathrm{E}$ in diets for laying hens: Effects on laying performance, storage stability and fatty acid composition of eggs. Arch. Geflügelkd., 1998, 62: 214-222.

43. Scheideler S.E., Froning G., Cuppett S. Studies of consumer acceptance of high omega-3 fatty acid-enriched eggs. J. Appl. Poult. Res., 1997, 6(2): 137-146 (doi: 10.1093/japr/6.2.137).

44. Fernandes Pereira A.L., Fontoura Vidal T., Gonçalves Abreu V.K., Fuentes Zapata J.F., Rodrigues Freitas E. Type of dietary lipids and storing time on egg stability. Ciênc. Tecnol. Aliment., 2011, 31(4): 984-991 (doi: 10.1590/S0101-20612011000400026).

45. Aghdam Shahryar H., Salamatdoust R., Chekain-Azar S., Ahadi F., $\mathrm{V}$ a hd at p o or T. Lipid oxidation in fresh and stored eggs enriched with dietary $\omega 3$ and $\omega 6$ polyunsaturated fatty acids and vitamin A and E dosages. Afr. J. Biotechnol., 2010, 9(12): 18271832 (doi: 10.5897/AJB10.1482).

46. Ch e k a n i a zar S. Unhealthy fats can be declined in enriched eggs by graded levels of polyunsaturated oils and selenium sources. J. Appl. Environ. Biol. Sci., 2011, 1(12): 711-715.

47. M a rshall A.C., S a m s A.R., V a n Elswyk M.E. Oxidative stability and sensory quality of stored eggs from hens fed 1.5\% menhaden oil. J. Food Sci., 1994, 59(3): 561-563 (doi: 10.1111/j.1365-2621.1994.tb05561.x).

48. C a st o n L., S qui res E.J., Le e s o $n$ S. Hen performance, egg quality, and the sensory evaluation of eggs from SCWL hens fed dietary flax. Can. J. Anim. Sci., 1994, 74(2): 347-353 (doi: 10.4141/cjas94-047).

49. Florou-Paneri P., Nikolakakis I., Giannenas I., Koidis A., Botsoglou E., Dotas V., Mits op oulos I. Hen performance and egg quality as affected by dietary oregano essential oil and -tocopheryl acetate supplementation. International Journal of Poultry Science, 2005, 4(7): 449-454 (doi: 10.3923/ijps.2005.449.454).

50. Onagbesan O., Bruggeman V., De Smit L., Debonne M., Witters A., To na K., Everaert N., D e cuypere E. Gas exchange during storage and incubation of avian eggs: Effects on embryogenesis, hatchability, chick quality and post-hatch growth. World's Poultry Sci. J., 2007, 63(4): 557-573 (doi: 10.1017/S0043933907001614).

51. Akter Y., Kas i m A., O mar H., S a z i li A.Q. Effect of storage time and temperature on the quality characteristic of chicken eggs. Journal of Food, Agriculture and Environment, 2014, 12(3-4): 87-92. 
52. R a harjo S., S o fos J.N., S c h midt G.R. Solid phase acid extraction improves thiobarbituric acid methods to determine lipid oxidation. J. Food Sci., 1993, 58(4): 921-924 (doi: 10.1111/j.1365-2621.1993.tb09391.x).

53. Scheideler S.E., Froning G.W. The combined influence of dietary flaxseed variety, level, form and storage conditions on egg production and composition among vitamin Esupplemented hens. Poultry Sci., 1996, 75(10): 1221-1226 (doi: 10.3382/ps.0751221).

54. Bubel F., Dobrzański Z., Bykowski P., Patkowska-Sokoła B., Trzisz$\mathrm{k}$ a $\mathrm{T}$. Enrichment of hen eggs with omega-3 polyunsaturated fatty acids - physiological and nutritional aspects. Acta Sci. Pol. Medicina Veterinaria, 2011, 10(3): 5-18.

55. Van Elswyk M.E., S chake L.S., H a rgis B.M., Ha rg is P.S. Effects of dietary menhaden oil on serum lipid parameters and hepatic lipidosis in laying hens. Poultry Sci., 1991, 70(Supp. 1): 122

56. Van Elswyk M.E., Proch ask a J.F., C are y J.B., Hargis P.S. Physiological parameters in response to dietary menhaden oil in molted hens. Poultry Sci., 1992, 71(Suppl. 1): 114.

57. He rkel R., Gálik B., Bíro D., Roli ne c M., ši mko M., J u ráč e k M., Majlá t M., A r p áš o vá H. The effect of pumpkin and flaxseed oils on selected parameters of laying hens performance. Acta Fytotechnica et Zootechnica, 2014, 17(3): 96-99 (doi: 10.15414/afz.2014.17.03.96-99).

58. Ha r ris W.S. Fish oils and plasma lipid and lipoprotein metabolism in humans: A critical review. J. Lipid Res., 1989, 30(6): 785-807.

59. Cherian G., Hay at Z. Long-term effects of feeding flaxseed on hepatic lipid characteristics and histopathology of laying hens. Poultry Sci., 2009, 88(12): 2555-2561 (doi: 10.3382/ps.2009-00425).

60. Phe t t e p la c e H.W., W a t k i n s B.A. Lipid measurements in chicken fed different combinations of chicken fat and menhaden oil. J. Agric. Food Chem., 1990, 38(9): 1848-1853 (doi: 10.1021/jf00099a013).

61. Konig B., Spielmann J., Ha as e K., Brandsch C., Kluge H., Stangl G.I., Ede r K. Effects of fish oil and conjugated linoleic acids on expression of target genes of PPAR and sterol regulatory element-binding proteins in the liver of laying hens. Br. J. Nutr., 2008, 100(2): 355-363 (doi: 10.1017/S0007114507883024).

62. White he ad C.C., B ow man A.S., Griffin H.D. Regulation of plasma oestrogen by dietary fats in the laying hen: relationships with egg weight. Brit. Poultry Sci., 1993, 34(5): 9991010 (doi: 10.1080/00071669308417659).

63. Va n E lsw y k M.E. Nutritional and physiological effects of flaxseed in diets for laying fowl. World's Poultry Sci. J., 1997, 53(3): 253-264 (doi: 10.1079/WPS19970020).

64. Thompson L.U., Robb P., S e rraino M., Che ung E. Mammalian lignan production from various foods. Nutr. Cancer, 1991, 16(1): 43-52 (doi: 10.1080/01635589109514139).

65. Ke n nedy A.K., D e a n C.E., A y mond W.M., Va n Elswyk M.E. Dietary flax seed influences pullet reproductive parameters. Poultry Sci., 1994, 73(Suppl. 1): 20.

66. Johns o n A.L., van Ti e hove n A. Effects of aminoglutethimide on luteinizing hormone and steroid secretion, and ovulation in the hen, Gallus domesticus. Endocrinology, 1984, 114(6): 2276-2283 (doi: 10.1210/endo-114-6-2276).

67. Crespo R., S hivap ras ad H.L. Developmental, metabolic and other non infectious disorders. In: Diseases of poultry. Y.M. Saif, H.J. Barnes, J.R. Glisson, A.M. Fadly, L.R. McDougald, D.E. Swayne (eds.). Iowa State University Press, Ames, 2003: 1048-1102.

68. J u li a n R.J. Production and growth related disorders and other metabolic diseases of poultry A review. The Veterinary Journal, 2005, 169(3): 350-369 (doi: 10.1016/j.tvjl.2004.04.015).

69. B e a n I.D., Le e s o n S. Long-term effects of feeding flaxseed on performance and egg fatty acid composition of brown and white hens. Poultry Sci., 2003, 82(3): 388-394 (doi: $10.1093 / \mathrm{ps} / 82.3 .388)$.

70. Van Els wyk M.E., H a rg is B.M., Willi a m s J.D., H a rg is P.S. Dietary menhaden oil contributes to hepatic lipidosis in laying hens. Poultry Sci., 1994, 73(5): 653-662 (doi: 10.3382/ps.0730653).

71. C h e ri a n G., G o e ge r M.P. Hepatic lipid characteristics and histopathology of laying hens fed CLA or n-3 fatty acids. Lipids, 2004, 39(1): 31-36 (doi: 10.1007/s11745-004-1198-2).

72. Schumann B.E., Squires E.J., Lees on S., Hunter B. Effect of hens fed dietary flaxseed with and without a fatty liver supplement on hepatic and plasma and production characteristics relevant to fatty liver haemorrhagic syndrome in laying hens. Brit. Poultry Sci., 2003, 44(2): 234-244 (doi: 10.1080/0007166031000087065).

73. Squires E.J., Le es o n S. Aetiology of fatty liver syndrome in laying hens. Brit. Vet. J., 1988, 144(6): 602-609 (doi: 10.1016/0007-1935(88)90031-0).

74. S u m m e rs J.D., A d a m s C.A., Le e s o n S. Metabolic disorders in poultry. Context Product Ltd., Packington (Leicester, UK), 2013: 109-130.

75. Farag M.M.A. Estimation of formatting biogenetic amines concentration in fresh and processed sardine fish products during different storage conditions. World J. Fish \& Marine Sci., 2013, 5(6): 628-636 (doi: 10.5829/idosi.wjfms.2013.05.06.7541).

76. $\mathrm{M} \mathrm{a} \mathrm{r} \mathrm{c} \mathrm{h} \mathrm{B.E.,} \mathrm{M} \mathrm{a} \mathrm{c} \mathrm{M} \mathrm{i} 11$ a $\mathrm{n} \mathrm{C}$. Trimethylamine production in the caeca and small intestine as a cause of fishy taints in eggs. Poultry Sci., 1979, 58(1): 93-98 (doi: 10.3382/ps.0580093). 
77. Honkatukia M., Reese K., Preisinger R., Tuiskula-Haavisto M., Weige nd S., Roito J., Mäki - T a nila A., Vilk ki J. Fishy taint in chicken eggs is associated with a substitution within a conserved motif of the FMO3 gene. Genomics, 2005, 86(2): $225-$ 232 (doi: 10.1016/j.ygeno.2005.04.005).

78. W a rd A.K., Clas e $\mathrm{n} \mathrm{H.L.,} \mathrm{B} \mathrm{u} \mathrm{chan} \mathrm{an} \mathrm{F.C.} \mathrm{Fishy-egg} \mathrm{tainting} \mathrm{is} \mathrm{recessively} \mathrm{inherited}$ when brown-shelled layers are fed canola meal. Poultry Sci., 2009, 88(4): 714-721 (doi: 10.3382/ps.2008-00430).

79. Va n Elsw y k M.E., D aw s o n P.L., S a m s A.R. Dietary menhaden oil influences sensory characteristics and headspace volatiles of shell eggs. J. Food Sci., 1995, 60(1): 85-89 (doi: 10.1111/j.1365-2621.1995.tb05612.x).

80. Sw ob od a P.A.T., P e e rs K.E. Volatile odorous compounds responsible for metallic, fishy taint formed in butterfat by selective oxidation. J. Sci. Food Agric., 1977, 28(11): 1010-1018 (doi: $10.1002 /$ jsfa.2740281110).

81. I g le si as J., L o is S., Medina I. Development of a solid-phase microextraction method for determination of volatile oxidation compounds in fish oil emulsions. J. Chromatogr. A, 2007, 1163(1-2): 277-287 (doi: 10.1016/j.chroma.2007.06.036).

82. H a rgis P.S., V a n E $1 \mathrm{~s}$ w y k M.E. Manipulating the fatty acid composition of poultry meat and eggs for the health conscious consumer. World's Poultry Sci. J., 1993, 49(3): 251-264 (doi: 10.1079/WPS19930023).

83. Moffat C.F., McGill A.S. Variability of the composition of fish oils: significance for the diet. Proceedings of the Nutrition Society, 1993, 52(3): 441-456 (doi: 10.1079/PNS19930085).

84. Albert B.B., Derraik J.G.B., Came ron-S mith D., Hofman P.L., Tumanov S., Villas-B o as S.G., Garg M.L., Cutfield W.S. Fish oil supplements in New Zealand are highly oxidised and do not meet label content of n-3 PUFA. Scientific Reports, 2015, 5: 7928 (doi: 10.1038/srep07928).

85. Gonzalez-Esquerra R., Le e s o n S. Effect of feeding hens regular or deodorized menhaden oil on production parameters, yolk fatty acid profile, and sensory quality of eggs. Poultry Sci., 2000, 79(11): 1597-1602 (doi: 10.1093/ps/79.11.1597).

86. L a w lor J.B., G a u d e t e N., D i cks o n T., H o u s e J.D. Fatty acid profile and sensory characteristics of table eggs from laying hens diets containing microencapsulated fish oil. Animal Feed Science and Technology, 2010, 156(3-4): 97-103 (doi: 10.1016/j.anifeedsci.2010.01.003).

87. K u ra Y., R e ve ng a C., $\mathrm{H}$ o s h i n o E., M o c k G. Fishing for answers: making sense from the global fish crisis. World Resources Institute, Washington, DC, 2004: 4-6.

88. Agboola A.F., O midiwura B.R.O., Oyeye mi A., Iy ay i E.A., Ade lani A.S. Effect of four dietary oils on cholesterol and fatty acid composition of egg yolk in layers. International Journal of Biological, Biomolecular, Agricultural, Food and Biotechnological Engineering, 2016, 10(2): 60-67.

89. O midi M., Rahimi Sh., Torshizi M.A.K. Modification of egg yolk fatty acids profile by using different oil sources. Vet. Res. Forum, 2015, 6(2): 137-141.

90. Fraeye I., Bruneel C., Le mahieu C., Buyse J., Muylaert K., Foubert I. Dietary enrichment of eggs with omega-3 fatty acids: A review. Food Res. Int., 2012, 48(2): 961969 (doi: 10.1016/j.foodres.2012.03.014).

91. $\mathrm{Ch}$ e n T.-F., H s u J.-Ch. Incorporation of n-3 long-chain polyunsaturated fatty acids into duck egg yolks. Asian-Australas. J. Anim. Sci., 2003, 16(4): 565-569 (doi: 10.5713/ajas.2003.565).

92. C a s t o n L.J., Le e s o n S. Dietary flax and egg composition. Poultry Sci., 1990, 69(9): 16171620 (doi: 10.3382/ps.0691617).

93. N e w k i r k R. Flax: Feed Industry Guide. Flax Canada 2015, Winnipeg, MB, 2008.

94. M o r r i s D.H. Flax: A health and nutrition primer. Flax Council of Canada, Winnipeg, MB, 2007.

95. She n Y., Feng D., O res anya T.F., Chave z E.R. Fatty acid and nitrogen utilization of processed flaxseed by adult chickens. J. Sci. Food Argic., 2005, 85(7): 1137-1142 (doi: 10.1002/jsfa.2073).

96. Feng D., She n Y., Chave z E.R. Effectiveness of different processing methods in reducing hydrogen cyanide content of flaxseed. J. Sci. Food Agric., 2003, 83(8): 836-841 (doi: 10.1002/jsfa.1412).

97. Ay mo nd W.M., V a n E $1 \mathrm{~s}$ w y k M.E. Yolk thiobarbituric acid reactive substances and n-3 fatty acids in response to whole and ground flaxseed. Poultry Sci., 1995, 74(8): 1388-1394.

98. Alzueta C., Rodriguez M.L., Cutuli M.T., Rebole A., Ortiz L.T., Cente no C., Tre vi no J. Effect of whole and demucilaged linseed in broiler chicken diets on digesta viscosity, nutrient utilization and intestinal microflora. Brit. Poultry Sci., 2003, 44(1): 67 74 (doi: 10.1080/0007166031000085337).

99. Slo minski B.A., Meng X., C a mpbell L.D., Guenter W., Jones O. The use of enzyme technology for improved energy utilization from full-fat oilseeds. Part II: Flaxseed. Poultry Sci., 2006, 85(6): 1031-1037 (doi: 10.1093/ps/85.6.1025).

100. Eg o rova T.A., Le n k o a T.N. Rapeseed (Brassica napus 1.) and its prospective useage in poultry diet (review). Agricultural Biology, 2015, 50(2): 172-182 (doi: 10.15389/agrobiology.2015.2.172eng) (in Eng.).

101. Jia W., Slominski B.A., Guenter W., Humphries A., Jones O. The effect of enzyme supplementation on egg production parameters and omega-3 fatty acid deposition 
in laying hens fed flaxseed and canola seed. Poultry Sci., 2008, 87(10): 2005-2014 (doi: 10.3382/ps.2007-00474).

102. L e e s o n S., S u m m e r s J.D. Ingredient evaluation and diet formulation: Flaxseed. In: Commercial poultry nutrition. S. Leeson, J.D. Summers (eds.). University Books, Guelph, Ontario, Canada, 2005: 44-46.

103. Goldberg E.M., Ryland D., Gibson R.A., Aliani M., House J.D. Designer laying hen diets to improve egg fatty acid profile and maintain sensory quality. Food Sci. Nutr., 2013, 1(4): 324-335 (doi: 10.1002/fsn3.47).

104. Le e s o n S., S u m m e r s J.D., C a s t o n L.J. Response of layers to dietary flaxseed according to body weight classification at maturity. J. Appl. Poult. Res., 2000, 9(3): 297-302 (doi: 10.1093/japr/9.3.297).

105. Weill P., Schmitt B., Chesneau G., Daniel N., Safraou F. Legrand P. Effects of introducing linseed in livestock diet on blood fatty acid composition of consumers of animal products. Ann. Nutr. Metab., 2002, 46(5): 182-191 (doi: 10.1159/000065405).

106. N a j ib H., A l-Y o u s e f Y.M. Essential fatty acid content of eggs and performance of layer hens fed with different levels of full-fat flaxseed. J. Cell Anim. Biol., 2010, 4(3): 58-63.

107. B rown Ch., Hamidu J., Adomako K. Paradigm shift in feeding layer birds for omega 3 eggs production. Proc. XXV World's Poultry Congr., Sep 5-9, 2016. Abstracts. Beijing, China, $2016: 42$.

108. Che rian G., Quezad a N. Egg quality, fatty acid composition and immunoglobulin Y content in eggs from laying hens fed full fat camelina or flax seed. J. Anim. Sci. Biotechnol., 2016, 7: 15 (doi: 10.1186/s40104-016-0075-y).

109. Lee Y.J., Kang S.K., Heo Y.J., Shin D.W., Park T.E., Han G.G., Jin G.D., Lee H.B., J ung E., K i m H.S., $\mathrm{N}$ a Y., K i m E.B., $\mathrm{C}$ h o i Y.J. Influence of flaxseed oil on fecal microbiota, egg quality and fatty acid composition of egg yolks in laying hens. Curr. Microbiol., 2016, 72(33): 259-266 (doi: 10.1007/s00284-0.15-0946-z).

110. Adarme-Vega T.C., Lim D.K.Y., Timmins M., Vernen F., Li Y., S chenk P.M. Microalgal biofactories: A promising approach towards sustainable omega-3 fatty acid production. Microbial Cell Factories, 2012, 11(1): 96 (doi: 10.1186/1475-2859-11-96).

111. Griffiths M.J., Harris o n S.T.L. Lipid productivity as a key characteristic for choosing algal species for biodiesel production. J. Appl. Phycol., 2009, 21(5): 493-507 (doi: 10.1007/s10811-008-9392-7).

112. Lu m K.K., Ki m J., Le i X.G. Dual potential of microalgae as a sustainable biofuel feedstock and animal feed. J. Anim. Sci. Biotechnol., 2013, 4(1): 53 (doi: 10.1186/2049-1891-4-53).

113. Schenk P.M., Thom as - Hall S.R., Ste phens E., Marx U.C., Mussgnug J.H., Poste n C., Kruse O., Ha n k a m e r B. Second generation biofuels: high-efficiency microalgae for biodiesel production. Bioenergy Res., 2008, 1(1): 20-43 (doi: 10.1007/s12155-008-9008-8).

114. Fredrikss on S., E 1 wi nge r K., P i ckova J. Fatty acid and carotenoid composition of egg yolk as an effect of microalgae addition to feed formula for laying hens. Food Chem., 2006, 99(3): 530-537 (doi: 10.1016/j.foodchem.2005.08.018).

115. P a rk J.H., U p ad h a y S.D., K i m I.H. Effect of dietary marine microalgae (Schyzochytrium) powder on egg production, blood lipid profiles, egg quality, and fatty acid composition of egg yolk in layers. Asian-Australas. J. Anim. Sci., 2015, 28(3): 391-397 (doi: 10.5713/ajas.14.0463).

116. Wu Y., Chang Y., Huang X., Li u W., Liao R., Zhang Sh., Yan H. Comparison of n-3 polyunsaturated fatty acid-enriched eggs from hens fed diets supplemented with microalgae and flaxseed. Proc. XXV World's Poultry Congr., Sep 5-9, 2016. Abstracts. Beijing, China, 2016: 531.

117. Bruneel Ch., Lemahieu Ch., Frayeye I., Ryckebosch E., Muylaert K., Buyse J., Foubert I. Impact of microalgal feed supplementation on omega-3 fatty acid enrichment of hen eggs. Journal of Functional Foods, 2013, 5(2): 897-904 (doi: 10.1016/j.jff.2013.01.039).

118. Ao T., Macalintal L., Paul M., Glenney Ph., Pescatore A., Cantor A., Ford M., D a w s o n K. Long term effects of dietary microalgae on productive performance of laying hens and egg docosahexaenoic acid concentration. Proc. XXV World's Poultry Congr., Sep 5-9, 2016. Abstracts. Beijing, China, 2016: 114.

119. $\mathrm{N}$ i m a la r a $\mathrm{n}$ e Ch., W u J. Hen egg as an antioxidant food commodity: A review. Nutrients, 2015, 7(10): 8274-8293 (doi: 10.3390/nu7105394).

120. G ülçi n I. Antioxidant activity of food constituents: An overview. Arch. Toxicol., 2012, 86(3): 345-391 (doi: 10.1007/s00204-011-0774-2).

121. H o ls e r R., H i n t o n A., Jr. Use of polyunsaturated fatty acids with -tocopherol in poultry feeds. Lipid Insights, 2010, 3(1): 1-4 (doi: 10.4137/LPI.S5788). 